\title{
Intradural chondroma in the cervical spine: case report
}

\author{
Yusuke Hori, MD, ${ }^{1}$ Masahiko Seki, MD, PhD, ${ }^{1}$ Tadao Tsujio, MD, PhD, ${ }^{1}$ \\ Masatoshi Hoshino, MD, PhD, ${ }^{2}$ Koji Mandai, MD, ${ }^{1}$ and Hiroaki Nakamura, MD, PhD²

\begin{abstract}
'Department of Orthopaedic Surgery and Spine Center, Shiraniwa Hospital, Ikoma, Nara; and 2Department of Orthopaedic Surgery, Osaka City University Graduate School of Medicine, Osaka, Japan
\end{abstract}

\begin{abstract}
Chondromas are benign tumors that are rarely located in the spine. The authors present a rare occurrence of a spinal chondroma that developed as an intradural but extramedullary tumor in a 60-year-old woman. The location of the tumor at C4-5 was confirmed by MRI, with hyperintensity on T2-weighted images and isointensity on T1-weighted images. The tumor was completely contained intradurally, with no continuity to any vertebrae. It adhered to the anterior dura, indicative of its likely origin from the dura mater. The tumor was completely resected, with no sign of recurrence after 3 years postoperatively. Although reports of chondromas originating from the dura mater have been previously described, these have all been intracranial tumors. To the best of the authors' knowledge, this is the first report of an intradural chondroma located in the spine. Therefore, chondromas should be considered in the differential diagnosis of intradural spinal tumors.
\end{abstract}

https://thejns.org/doi/abs/10.3171/2016.8.SPINE16152

KEY WORDS chondroma; intradural tumor; cervical spine; spinal tumor; oncology

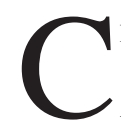
HONDROMAS are benign tumors of cartilaginous tissue that rarely present as primary spinal tumors. According to Dahlin's series of benign bone tumors, $11.2 \%$ of benign bone tumors are chondromas, with only $4 \%$ of these chondromas presenting as spinal tumors. ${ }^{8}$ Only 13 cases of chondromas located in the cervical spine have been reported. ${ }^{16}$ Meningeal chondromas are also rare and have been reported only as intracranial tumors. Although 20 cases of chondromas originating at the convexity of the dura mater have been described, ${ }^{1}$ to the best of our knowledge, there has been no report of a meningeal chondroma located in the spine. The aim of our case report was to describe a case of intradural chondroma located in the cervical spine.

\section{Case Report}

History and Examination

A 60-year-old woman presented with a 3-month history of progressive neck and right upper-extremity pain. On physical examination, the results of the Jackson and Spurling tests were positive on the right side. Deep tendon reflexes were normal, with the exception of weakness of the right biceps tendon reflex. No motor weakness or symptoms of myelopathy were identified.

Findings on radiographs and CT scans were largely unremarkable, with only mild spondylosis identified. On MRI, a round tumor was identified at the level of C4-5.
The tumor was isointense on T1-weighted images and hyperintense on T2-weighted images. The location of the tumor was intradural but extramedullary, with no continuity with the adjacent vertebrae. The tumor compressed the right side of the spinal cord (Fig. 1).

\section{Operation}

Right hemilaminectomy and foraminotomy at the level of $\mathrm{C} 4-5$ were performed under microscopic visualization. The tumor was not apparent from outside the dura. After opening the dura, an intradural but extramedullary pale yellow tumor was identified. Due to adherence of the tumor to the anterior dura, we assumed the tumor originated from the dura. Complete resection was performed in a piecemeal fashion, with sacrifice of the anterior dura. The dural defect was repaired using the free flap from the fascia of the neck.

\section{Histopathological Examination}

Histological examination confirmed that the tumor consisted of chondroid tissue. The chondrocytes had slightly large nuclei, with no evidence of malignancy. Based on histological findings, a diagnosis of chondroma was made (Fig. 2).

\section{Postoperative Course}

Postoperatively, the patient's right neck and right upper- 

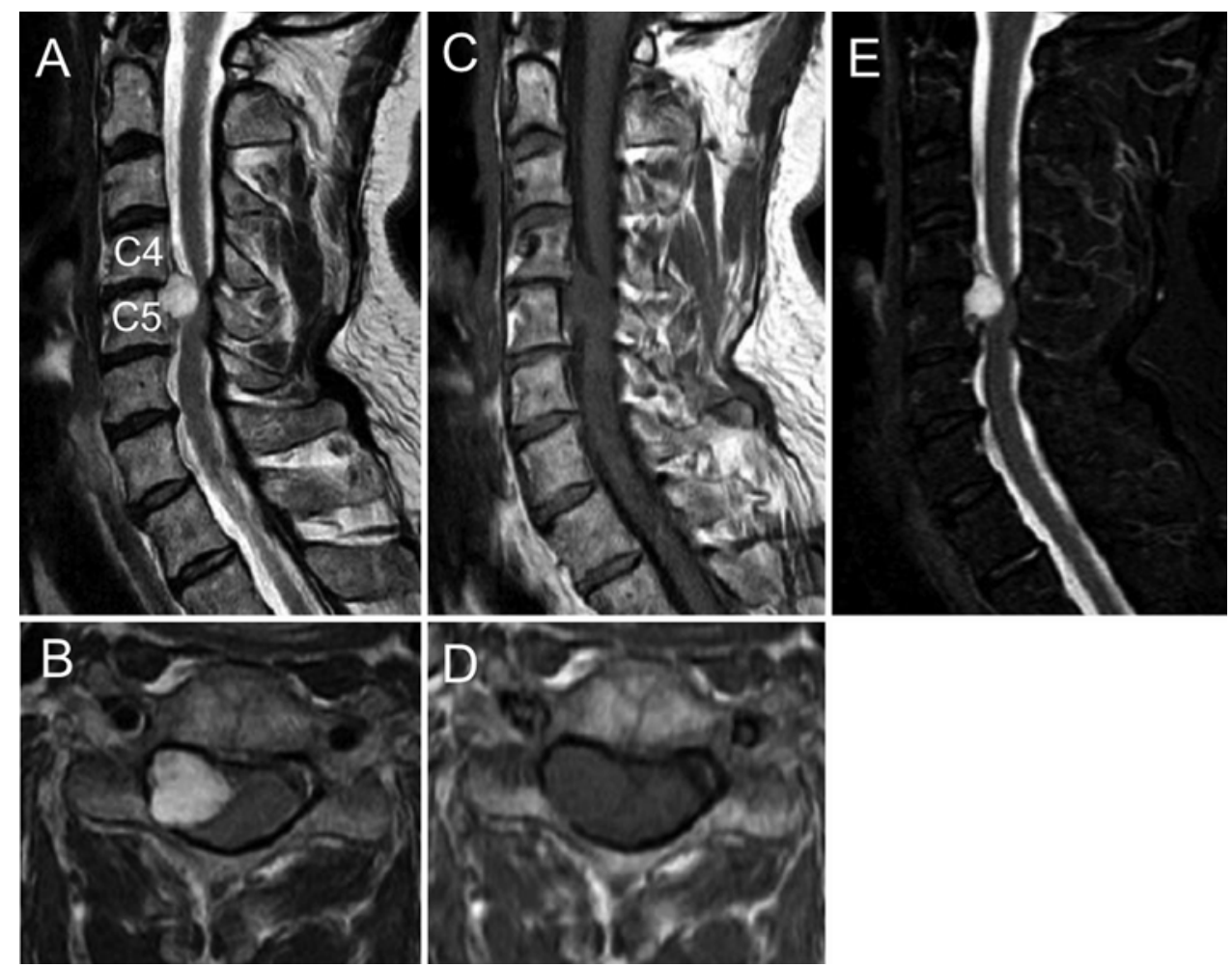

FIG. 1. Preoperative parasagittal and axial MR images showing an intradural but extramedullary mass at the level of C4-5. Hyperintensity on T2-weighted images ( $A$ and $\mathbf{B}$ ), isointensity on T1-weighted images (C and $\mathbf{D}$ ), and hyperintensity on a short tau inversion recovery image $(\mathrm{E})$ showing spinal cord compression by the mass.

extremity pain resolved immediately. A right C-5 nerve paralysis was identified postoperatively but gradually improved, with complete recovery of deltoid muscle strength. There was no sign of tumor recurrence after 3 years of follow-up (Fig. 3).

\section{Discussion}

Chondromas are benign tumors of the cartilaginous tissue and include enchondromas or periosteal chondromas, osteochondromas, chondroblastomas, and chondromyxoid fibromas. ${ }^{4}$ Chondromas may present either as a single lesion or as multifocal lesions and may demonstrate metaplasia or malignant degeneration to a chondrosarcoma. ${ }^{9}$ The occurrence of chondromas is twice as common in men as in women, with the incidence rate being highest in 20- to 40-year-old adults. ${ }^{3}$

Although chondromas occur predominantly in the small bones of the hands and feet, they can develop in any bone. Moreover, chondromas can also arise from muscle tendon or synovial sheaths. ${ }^{12}$ Russo et al. ${ }^{16}$ summarized cases of chondromas localized to the cervical spine, with evidence that most spinal chondromas arise from the vertebral body, the neural arc (pedicle or lamina), or the spinous process. No reports of chondromas arising from the dura mater of the spine have been published to date. By comparison, about 20 cases of intracranial dural chondromas, arising from the convexity or the falx cerebri, have been reported in the literature. ${ }^{1}$ Although various hypotheses regarding the origin of intracranial chondromas have been presented, the pathogenesis of the chondromas re- mains controversial. It has been suggested that intracranial chondromas develop from heterotopic chondrocytes, ${ }^{15}$ are secondary to metaplasia of meningeal fibroblasts or perivascular mesenchymal tissues, ${ }^{2,5}$ or are secondary to the cartilaginous activation of fibroblasts by trauma or inflammation. ${ }^{11}$

MRI is useful in defining the location and extent of a chondroma. On MRI, most chondromas show intermediate signal intensity on T1-weighted images and high signal intensity in the central part of the mass on T2-weighted images. ${ }^{6}$ The hyaline cartilage, which has high water content, typically shows homogeneously high signal intensity on T2-weighted images. ${ }^{7}$ In our case, T1-weighted images showed uniform isointensity, and T2-weighted images showed uniform hyperintensity. These results are consistent with imaging findings for chondromas that have been previously reported in the literature. However, these
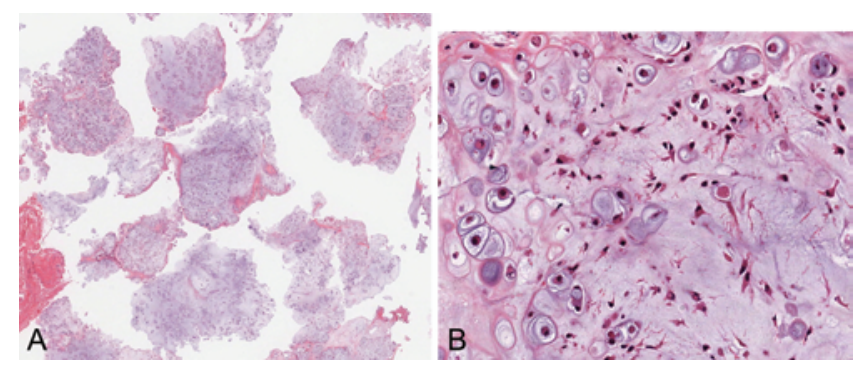

FIG. 2. Photomicrographs showing the growth of cartilaginous cells with slight atypia. H \& E, original magnification $\times 14$ (A) and $\times 200$ (B). Figure is available in color online only. 


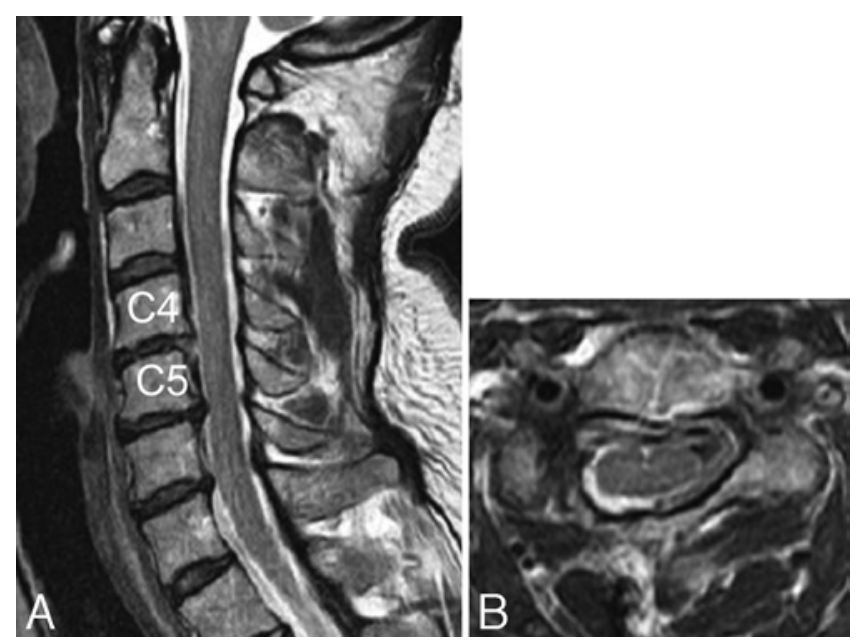

FIG. 3. Parasagittal (A) and axial (B) MR images obtained 3 years after surgery, showing complete resection of the chondroma.

findings are very similar to most intradural but extramedullary tumors. Schwannomas and meningiomas are the most common of these intradural extramedullary tumors. Neurofibromas and other rare tumors, such as ependymoma, paraganglioma, hemangioma, and teratoma, can also develop as intradural extramedullary tumors on occasion. On MRI, schwannomas and neurofibromas are isointense on T1-weighted imaging and hyperintense on T2-weighted imaging, with schwannomas presenting with mixed signal intensity on T2-weighted imaging on occasion. Meningiomas are commonly isointense on both T1- and T2weighted imaging, with some of these tumors exhibiting hyperintensity on T2-weighted imaging. ${ }^{17}$ Therefore, differentiating chondromas from these other tumors by using MRI is difficult, particularly if a chondroma is not being considered as a differential diagnosis for an intradural extramedullary mass.

The standard and only effective treatment for a chondroma is complete resection. ${ }^{10,14}$ Following complete resection of a chondroma, the recurrence rate of chondromas is less than $10 \% .^{12}$ However, according to Nora et al., recurrence of a chondroma always results in cases of incomplete removal. ${ }^{13}$ Chemotherapy is ineffective, and the lesions are not responsive to radiotherapy. ${ }^{4}$

\section{Conclusions}

Chondromas are rarely located in the spine. In fact, meningeal chondromas have been reported as intracranial tumors in only a few previously published reports. To the best of our knowledge, our case is the first report of a dural chondroma located in the spine. Based on our experience, we propose that chondromas should be considered as a differential diagnosis in the assessment of intradural spinal tumors.

\section{References}

1. Abeloos L, Maris C, Salmon I, Balériaux D, Sadeghi N, Lefranc F: Chondroma of the dural convexity: a case report and literature review. Neuropathology 32:306-310, 2012
2. Ahyai A, Spoerri O: Intracerebral chondroma. Surg Neurol 11:431-433, 1979

3. Antić B, Roganović Z, Tadić R, Ilić S: Chondroma of the cervical spinal canal. Case report. J Neurosurg Sci 36:239241, 1992

4. Bell MS: Benign cartilaginous tumours of the spine. A report of one case together with a review of the literature. Br J Surg 58:707-711, 1971

5. Berkmen YM, Blatt ES: Cranial and intracranial cartilaginous tumours. Clin Radiol 19:327-333, 1968

6. Chandramohan M, Thomas NB, Funk L, Muir LT: MR appearance of mineralized extra skeletal chondroma: a case report and review of literature. Clin Radiol 57:421-423, 2002

7. Cohen EK, Kressel HY, Frank TS, Fallon M, Burk DL Jr, Dalinka MK, et al: Hyaline cartilage-origin bone and softtissue neoplasms: MR appearance and histologic correlation. Radiology 167:477-481, 1988

8. Dahlin DC: Bone Tumors: General Aspects and Data on 6221 Cases, ed 3. Springfield, IL: Charles C Thomas, 1978, pp 28-41

9. Fahim DK, Johnson KK, Whitehead WE, Curry DJ, Luerssen TG, Jea A: Periosteal chondroma of the pediatric cervical spine. J Neurosurg Pediatr 3:151-156, 2009

10. Fountas KN, Stamatiou S, Barbanis S, Kourtopoulos H: Intracranial falx chondroma: literature review and a case report. Clin Neurol Neurosurg 110:8-13, 2008

11. Hong JT, Lee SW, Son BC, Sung JH, Choi HC, Kim MC: Delayed occurrence of intracranial supratentorial chondroma following compound depressed skull fracture. Acta Neurochir (Wien) 147:343-345, 2005

12. Morard M, De Tribolet N, Janzer RC: Chondromas of the spine: report of two cases and review of the literature. Br J Neurosurg 7:551-556, 1993

13. Nora FE, Dahlin DC, Beabout JW: Bizarre parosteal osteochondromatous proliferations of the hands and feet. Am J Surg Pathol 7:245-250, 1983

14. Ogata T, Miyazaki T, Morino T, Nose M, Yamamoto H: A periosteal chondroma in the lumbar spinal canal. Case report. J Neurosurg Spine 7:454-458, 2007

15. Russell DS: Meningeal tumours: a review. J Clin Pathol 3:191-211, 1950

16. Russo V, Platania N, Graziano F, Albanese V: Cervical spine chondroma arising from $\mathrm{C} 5$ right hemilamina: a rare cause of spinal cord compression. Case report and review of the literature. J Neurosurg Sci 54:113-117, 2010

17. Soderlund KA, Smith AB, Rushing EJ, Smirniotopolous JG: Radiologic-pathologic correlation of pediatric and adolescent spinal neoplasms: Part 2, Intradural extramedullary spinal neoplasms. AJR Am J Roentgenol 198:44-51, 2012

\section{Disclosures}

The authors report no conflict of interest concerning the materials or methods used in this study or the findings specified in this paper.

\section{Author Contributions}

Conception and design: Hori. Acquisition of data: Hori. Drafting the article: Hori. Critically revising the article: Hori. Reviewed submitted version of manuscript: Seki, Tsujio, Hoshino, Mandai, Nakamura. Study supervision: Seki, Nakamura.

\section{Correspondence}

Yusuke Hori, Department of Orthopaedic Surgery, Shiraniwa Hospital, 6-10-1 Shiraniwadai, Ikoma 630-0136, Japan. email: yusukehori0702@gmail.com. 